Research Article

\title{
Establishment and Application Study of Digital Model for Coal Microstructure Based on CT Images
}

\author{
Wang Gang ${ }^{1,2}$, Zhang Xiaoqiang ${ }^{2 *}$, Yang Xinxiang ${ }^{2}$, Sun Lulu ${ }^{2}$ and Qu Hongyuan ${ }^{3}$ \\ ${ }^{I}$ State Key Laboratory of Coal Mine Disaster Dynamics and Control, Chongqing 400030, China \\ ${ }^{2}$ College of Mining and Safety Engineering, Shandong University of Science and Technology, Qingdao 266590, China \\ ${ }^{3}$ Colorado School of Mines, Colorado 80402, United States
}

Received 30 July 2016; Accepted 3 September 2016

\begin{abstract}
The construction of coal body microstructure is the foundation of realizing the organic combination of coal micro seepage experiment and simulation. In light of the problem that traditional experimental methods cannot directly reveal the coal microstructure, a three-dimensional (3D) digital model for coal microstructure based on non-contact computed tomography (CT) images was developed here. Firstly, the high-precision micro-CT system $\mu \mathrm{CT} 225 \mathrm{KvFCB}$ was used to obtain two-dimensional (2D) CT images of the coal core. Secondly, a CT image pre-processing methodical approach was developed. Furthermore, this paper proposed the gray level threshold segmentation (DTM) method as a way to obtain binary images for CT images. Thirdly, the CT images obtained above were then stacked to produce a 3D digital reconstruction model of the coal core. Taking the Shanxi Changzhi anthracite and Anhui Wugou long-flame coal, which have different degrees of metamorphism, as examples, an application of the quantitative parameters of the internal pore structure of the digital reconstruction model was calculated. The porosity experimental results obtained using the mercury intrusion method were analyzed to confirm the accuracy of the reconstruction process. Results show the 3D reconstruction models is fit to reveal the real pore structure of the coal microstructure and the porosity error obtained between the reconstruction model and laboratory analysis was less than $5 \%$. The proposed 3D reconstruction method in the present study is capable of visually and quantitatively describing the characteristics of microstructure and porosity of raw coal.
\end{abstract}

Keywords: Coal, CT image, Pore structure, DTM threshold segmentation, 3D reconstruction

\section{Introduction}

Permeability is an important parameter for characterizing coal reservoirs as well as for evaluating coal bed methane production potential. Raw coal contains many internal pores and fissures that directly influence physical and mechanical properties of coal microstructure, such as gas absorption, strength, hydroscopicity, and permeability. In the practical research of coal and gas outburst, coal gas content, desorption velocity, gas emission intensity and attenuation law and gas resource evaluation and development are related to the study of coal pore structure [1]. For very lowpermeability coal, the quantitative characterization of pore structures and their evolution characteristics in coal from the microscopic perspective are important. However, raw coal is deeply buried underground, and its internal microstructure, gas desorption and the effects of geological stresses are invisible and untouchable. One of the possible methods to understand those processes is to use mathematical modeling on basis of raw coal. Instead of adopting some laboratory techniques to obtain some permeability indirectly representing the pore structure, searching for a reliable digital model to achieve accurate representation of the macro

*E-mail address: kdyoung@126.com

ISSN: $1791-2377$ @ 2016 Eastern Macedonia and Thrace Institute of Technology. All rights reserved. parameters of coal is necessary and useful for further study of the coal micro mechanical behavior.

\section{State of the art}

The study of the pore structure of coal currently relies on observation and field detection methods and conventional experiments such as the mercury intrusion and nitrogen adsorption methods [2]. Those methods are intractable to relate the characterization of pore structure to gas desorption. Considering the difficulty of determining directly the coal pore microstructure via laboratory test, using computermodeling techniques is therefore imperative to investigate pore scale and microstructure of coal. In the present research field of coal pore, the methods to reconstruct pore space model are generally divided into two main categories. The first category is stochastic reconstruction of pore space using statistical methods. However, obtaining the distribution parameters of pore space is difficult. Thus, accurate description is quite impossible for the pore structure properties. Another method is using the images of the coal obtained directly by various scan techniques to construct the digital model of the pore structure [3]. In recent years, the non-contact computed tomography (CT) technology has become a powerful tool to achieve the goal and had been extensively used [4]. This method can describe the internal 
structure of an object dynamically and quantitatively without damage or change it. Using this technology, researchers are able to extract the information of mineral composition and microstructure of objects.

In the 1980s, CT technology appeared in the medical field and has since been used in the research of material defect detection and rock structure [5]. Kawakata reconstructed three-dimensional (3D) structure of granite using the CT image resampling method [6]. Vogel used a CT scan image to analyze soil samples and established a 3D porous model [7]. Yang pioneered the use of CT recognition technology in detecting damage and assessment of changes in the rock microstructure during compression [8]. However, the main research objects of those studies are rocks. Ge conducted a real-time dynamic test and observed the entire process of the development of coal microscopic damage evolution law under triaxial and uniaxial load [9]. Peng combined fractal theory with digital image processing technology and discussed the relationship between porosity and fractal dimension [10]. Gong computed multi-scale features of fissures and pores by using scanning electron microscopy (SEM) and CT images based on the image processing and analysis technologies [11]. As a type of rock, coal has heterogeneous porous characteristics that are more complex. In the aforementioned studies, the object of study is coal. However, the resolution of the CT machine is not high, thereby resulting in an unclear effect of the pore structure reconstruction.

Measuring the pore structure characteristics is possible using traditional test methods, including determining the pore size distribution within a certain range and identifying the pore type in coal. However, the results obtained are solely in the macroscopic two-dimensional (2D) space with limited characterizations. Furthermore, those testing processes generally destroy the coal core microstructure, thereby resulting in a larger deviation than real coal. The method of CT technique is able to obtain pore parameters and quantitative characteristics of the microscopic pore structure of coal while minimizing damage as much as possible. The method is also able to establish visual digital models using 3D image reconstruction techniques.

In this study, we discussed the techniques of combining theoretical analysis, image processing, and the methods of laboratory experiments with the $3 \mathrm{D}$ reconstruction technology based on 2D CT images. This study also conducted 3D reconstruction of thin-section samples of Shanxi Changzhi anthracite coal and Anhui Wugou longflame coal. Combined with experimental laboratory analysis and reconstructed digital models, the study verified the accuracy of the reconstruction model of coal microstructure. The discussions also established further directions for the study of the microstructure properties of digital model reconstruction.

\section{Methodology}

In order to obtain the pore structure model that could represent the actual microstructure of coal core and realize the organic combination of microscopic experiment and simulation, the key technology that must be solved is constructing 3D coal porous models. Specifically, this study seeks solutions for the following: establishing of coal body microstructure description and network model using the 3D reconstruction technology and realizing the transformation of the 2D CT image information to the 3D structure of coal pore distribution and topology information.

Creating a geometric model is the first step to simulate numerically of coal bed gas seepage in coal and rock mass. The structure of pore and fracture of coal and rock mass is small, and the conventional test method is difficult to observe. Using CT technology, distributing hole and crack structure in 2D plane is possible using the chromatography scanning of coal and rock mass, namely, CT slice. A series of 2D slices are processed by threshold segmentation, and then the data interpolation between slices is carried out. Furthermore, the 3D distribution of the pore structure is obtained by the operation of spatial stacking. The entire process can be called CT 3D reconstruction.

\subsection{Pore microstructure of coal samples}

The size of the pores in coal is not uniform. The pores can be classified as micro pores (diameter $<0.01 \mu \mathrm{m}$ ), which increase the coal adsorption volume; holes $(0.01 \mu \mathrm{m}$ to 0.1 $\mu \mathrm{m})$, which consist of capillary condensation and gas diffusion space; and large aperture pores $(0.1 \mu \mathrm{m}$ to $100 \mu \mathrm{m})$, which increase the gas permeability spaces.

The available pore size distribution can be determined using the mercury intrusion method or nitrogen adsorption isotherm method. Previous studies had shown that the pore size distribution of coal with different coalification degrees has a certain regularity: the higher the degree, the smaller the pore size. The significantly large proportion of micro pores in the pore volume reflects that the physical structure of coal tends to be tight. Figure 1 (a) shows a SEM image of highly metamorphic anthracite, whereas Figure 1 (b) shows a SEM image of low-grade metamorphic long-flame coal.

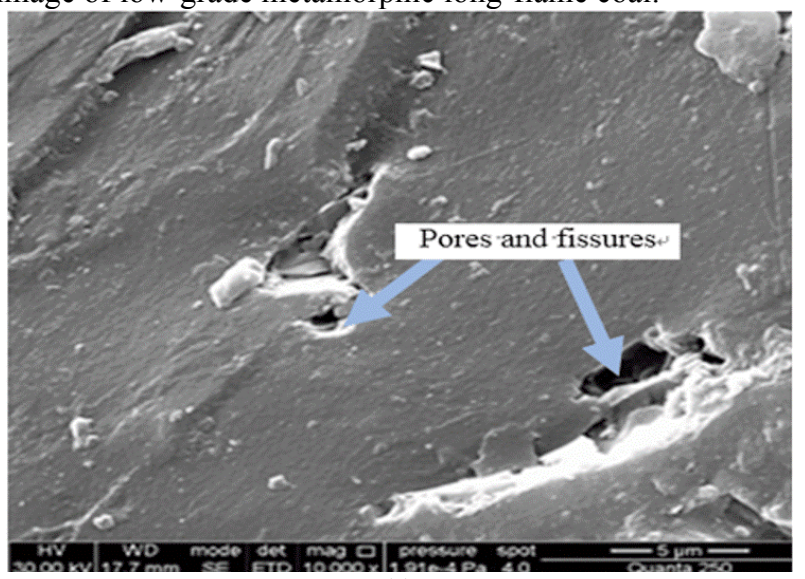

(a)

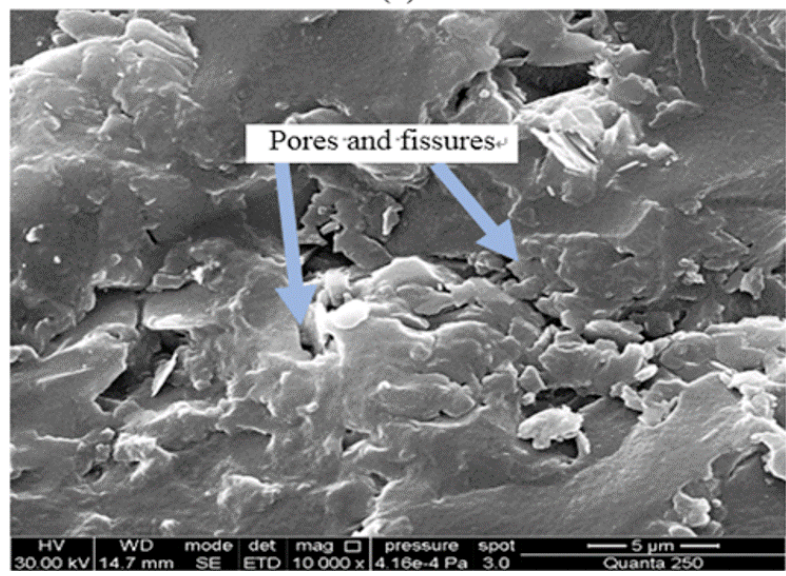

(b)

Fig. 1. SEM images of raw coal samples. (a) Anthracite, (b) Longflame coal 
Notably, the surface of anthracite was smooth with no evident fractures, whereas the surface of long-flame coal has many pores and fissures. Therefore, as the rank decreases, large pores gradually become apparent on the coal surface. Specifically, the lower the degree of coal metamorphism, the higher the degree of development of the coal pore system. But the internal pore shape and distribution characteristics of coal cannot be expressed by the method.

\subsection{Industrial CT scanning and imaging principle}

Industrial CT scanning technology is based on industrial CT scanning devices. These devices consist of three parts [12], namely, scanning component, computer system, storage unit and image display system. The basic principle of CT scanning devices is as follows: when the X-ray scans an object of a certain thickness, the detector receives the X-ray and translates it into visible light, and converts the light into electrical signals. After the analog/digital conversion of the signal, the information is input into the computer for further processing. The X-ray photon attenuation coefficient of coal pore and material is different, as well as the X-ray input and output. Then, the density distribution of coal is determined. Based on a matrix arrangement, CT images are produced [13, 14]. The coal core CT scanning process is shown in Figure 2.

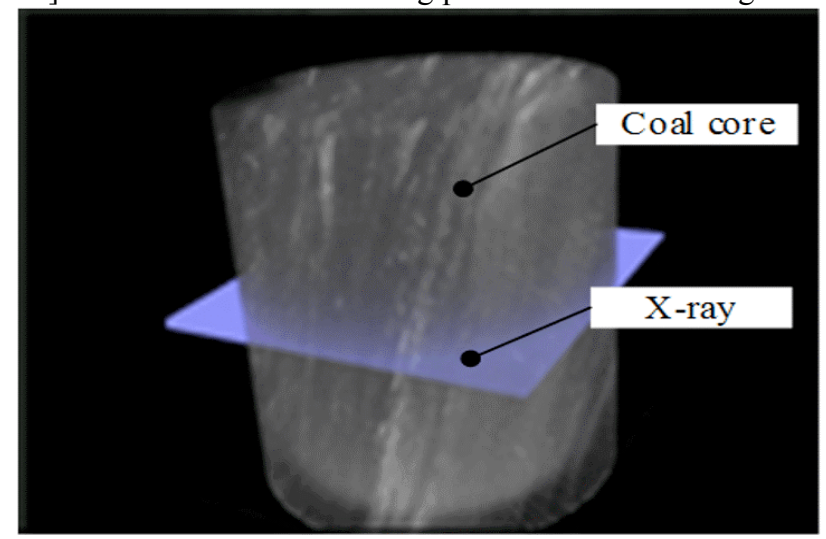

Fig. 2. Coal core CT scan process schematic

When X-rays emitted from the CT device penetrate the objects, their light intensity can be calculated via the following equation:

$$
I=I_{0} \exp \left(-\mu_{m} \rho x\right)
$$

where,

$I_{0}=$ light intensity of X-ray before penetrating coal,

$I=$ light intensity of X-ray after penetrating coal,

$\mu_{m}=$ absorption coefficient for the mass of the coal being detected,

$$
\rho=\text { coal density, and }
$$

$x=$ penetration length of the incident X-ray.

We also considered a previous work [15] of Formulas (2) and (3), as follows:

$$
\begin{aligned}
& \mu=\mu_{m} \rho=\rho\left(a+b \frac{Z^{3.8}}{E^{3.2}}\right) \\
& p=-\ln \left(\frac{I}{I_{0}}\right)=\int_{L} \mu d x
\end{aligned}
$$

where,

$$
\begin{aligned}
& p=\text { projection measured value }, \\
& Z=\text { atomic number, } \\
& a=\text { Klein-Nishina coefficient } \\
& b=9.8 \times 10^{-24}, \text { and } \\
& E=\text { X-ray particle energy. }
\end{aligned}
$$

In practical applications, $\mathrm{CT}$ values are used to measure the gray level of the $\mathrm{CT}$ image obtained by comparing attenuation coefficient and water, as shown in Formula 4. The absorption coefficient and CT values of the X-ray are determined in terms of the following expression:

$$
C T(H)=\frac{\mu-\mu_{m}}{\mu_{m}} \times 1000
$$

\subsection{Coal CT image reconstruction process}

In the reconstruction technique, $3 \mathrm{D}$ data are generated from a certain process. The $3 \mathrm{D}$ volume of coal samples can be obtained by extracting the geometric model of the reconstructed coal microstructure, which is also known as the real digital model. The ultimate goal of 3D reconstruction is to produce a coal pore structure model that can be used in numerical simulation analysis and in the calculation of the porosity of coal. The reconstruction process has four steps, which are discussed in detail below.

\section{(1) Coal core production and CT scan}

A coal pillar was drilled using a glass drill and fine sandpaper. Coal samples were collected for comparison experiments. All coal samples must be collected from the same location. The production process must ensure the integrity of the coal core. The influence of specific parameters on the CT system and magnification bust must be removed to determine the scanning length and position. Then, the samples were scanned to produce 2D CT images. Coal pillar diameter and length are shown in Figure 3.

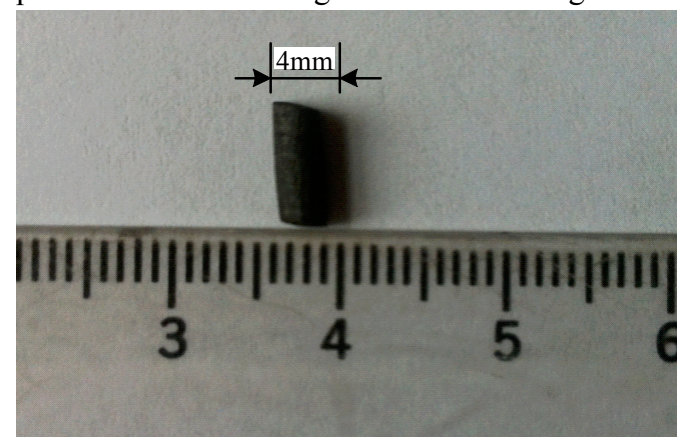

(a)

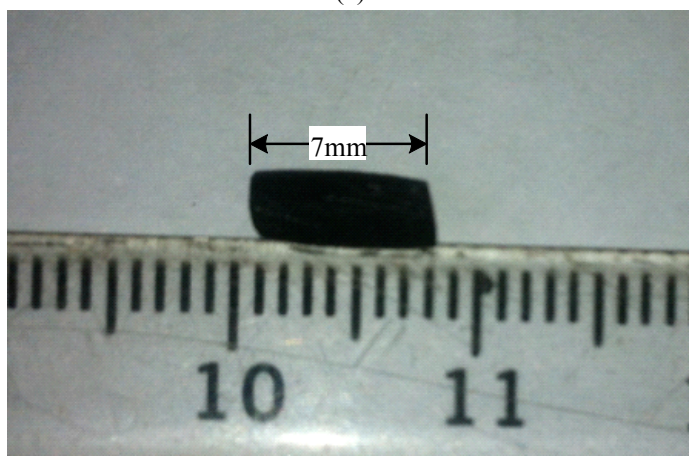

(b)

Fig. 3. Diameter and length of the scanned coal pillar. (a) Diameter, (b) Length

Preprocessing of the coal samples can affect the coal structure. The surface of the coal samples was irregular in shape and covered with holes, thereby rendering the contour 
of the CT images irregular and accompanied with small noise. Trimming the CT images was necessary to remove the influence of the boundary and balance the amount of data reconstruction to calculate capacity. The central part of the
CT scan image was the least affected, which was generally subject to our actual requirements. Then, the rectangular area of a certain pixel size in the region is selected as the target area of the pending reconstruction process.

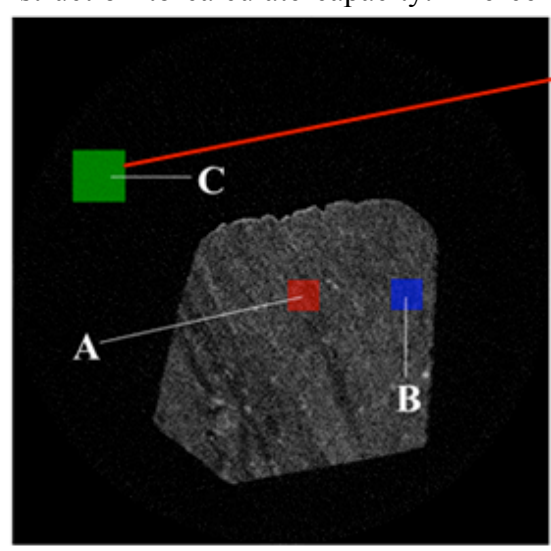

(a) Coal core CT image

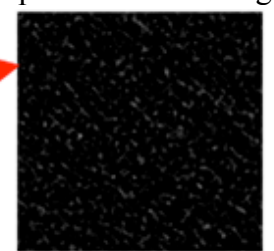

(b) Before denoising

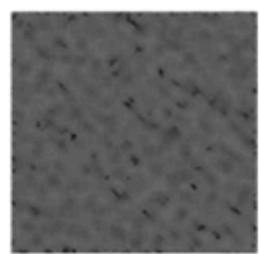

(d) After dencising

Fig. 4 CT slices of coal specimens and before and after denoising

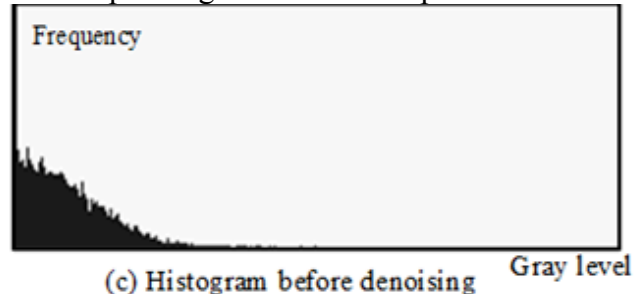

(c) Histogram before denoising

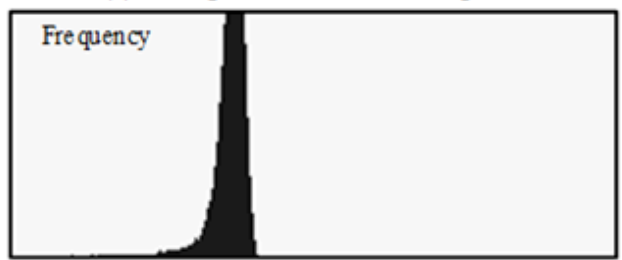

(e) Histogram after denoising

Gray level

\section{(2) 2D CT image processing}

The raw CT scan images have a large amount of noises, which are usually generated by the $\mathrm{CT}$ system and the environment, and are unable to be used directly. Measures must be taken to remove those noises. Using the noise identification technology, we determined that the existing noise in CT scan images was mainly Gaussian noise $[16,17]$ The Wiener filter exhibited a good noise removal effect on Gaussian noise (Fig. 4). The $\mathrm{C}$ area in Figure 4 corresponded to air. The density was uneven. The gray value of the image pixels should be concentrated and kept within a small range when reflected in CT images. However, the distribution of the gray value was broad because of the presence of noise.

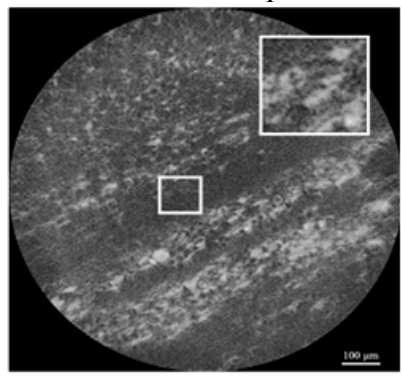

Step 1: CT scan and image segmentation real coal digital model
Noise evidently existed in the image (white spots in Figure 4(b)). Via the Wiener filtering denoising operation, the effect of noise can be reduced, and the gray values are concentrated (Figure 4(c)). The obtained CT image after denoising is shown in Figure 4(d).

(3) 3D data stream establishment

The current methodology enables the design and development of new porous microstructures and the analysis of the existing microstructures of 2D images. The processed 2D CT images were arranged in the space structure and imported into 3D reconstruction software for reconstruction [18].

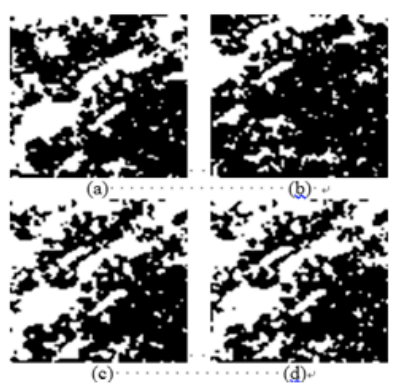

Step 2: Noise processing threshold segmentation

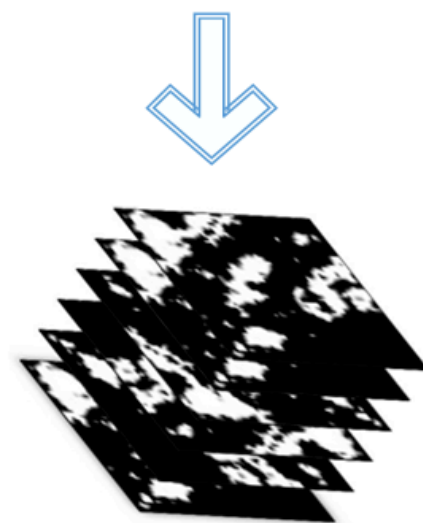

Step 3: 3D data flow stack

Fig. 5. CT reconstruction process: 2D to $3 \mathrm{D}$ obj 
(4) Establishment of the real digital model of the coal core

At present, two methods are applied for 3D reconstruction, namely, volume rendering, and surface rendering. With the development of computer technology, surface rendering has shown only a few interactive advantages. Volume rendering is more prominent than surface rendering as it consider the process of all elements. We may confidently anticipate that volume rendering will become more popular, thereby implying its possible replacement of surface rendering techniques in many applications. Based on MATLB, we can compile $3 \mathrm{D}$ reconstruction software based on the volume rendering method. This software can meet the needs of the $3 \mathrm{D}$ reconstruction of the coal core, and show the discontinuous behavior of coal. The reconstruction procedure employed is summarized in Figure 5.

\subsection{Threshold segmentation method based on CT image gray level}

Pore fracture is one of the important characteristics of coal. 2D CT images are not binary-valued. Therefore, accurate threshold segmentation is the basis of the precise characterization of coal microstructure, and is a key step in determining whether the reconstructed model can accurately describe the physical structure of coal.

In the process of dealing with 2D CT images, the number of coal pores in the CT image may increase or decrease with different threshold segmentation methods, even in the same CT image. The user may select different threshold segmentation algorithms or thresholds, thereby resulting in larger subjective calculation results. Therefore, the traditional CT image analysis process has strong randomness or uncertainty features. In this paper, the threshold segmentation method, also called the gray level method, is determined based on the principle of $\mathrm{CT}$ image formation. The scanned images were viewed as a matrix of different gray values. The gray level of the CT image can be compared with the digital terrain model (DTM). The gray value was equivalent to ground elevation in DTM. The images with maximum gray value that correspond to the pore and fracture volumes $V_{E}$ and the total volume of coal $V_{T}$ can be expressed as follows:

$$
\begin{aligned}
& V_{E}=v \sum_{r_{i}=r_{\text {min }}}^{r_{\text {max }}}\left(r_{\text {max }}-r_{i}\right) H\left(r_{i}\right) \\
& V_{T}=v \sum_{r_{i}=r_{\text {min }}}^{r_{\text {max }}}\left(r_{\text {max }}-r_{\text {min }}\right) H\left(r_{i}\right)
\end{aligned}
$$

where

$$
\begin{aligned}
& r_{\min }=\text { minimum gray value of the image, } \\
& r_{\max }=\text { maximum gray value of the image, } \\
& r_{i}=\text { gray value of each pixel, } r_{i} \in\left[r_{\min }, r_{\max }\right] \\
& v=\text { unit pixel volume, and } \\
& H\left(r_{i}\right)=\text { gray histogram in the range of }\left[r_{\min }, r_{\max }\right], \text { its }
\end{aligned}
$$

value can be calculated as follows:

$$
H\left(r_{i}\right)=\frac{n_{i}}{n}
$$

where

$$
n_{i}=\text { the number of pixels in the image, }
$$

$$
n=\text { the sum of the image pixels, and } \sum_{r_{i}=r_{\min }}^{r_{\max }} H\left(\mathrm{r}_{\mathrm{i}}\right)=1 \text {. }
$$

When the gray value of the individual pixel in the image is relatively higher, the calculated porosity will be larger than the real value. Imbalance between the pore volume $V_{E}$ and the total coal volume $V_{T}$ was observed. The values of $V_{E}$ and $V_{T}$ all change with the threshold value $x$. The change in the threshold is restricted in the range of $\left[r_{\min }, r_{\max }\right]$. The maximum value of $x$ is $r_{\max }$. When the value of $x$ is greater than $r_{\text {max }}$, the obtained porosity is meaningless. After optimization, the relationship between gray value and porosity can be expressed as follows:

$$
\phi(x)=\frac{V_{E}}{V_{T}}=\frac{\sum_{r_{i}=0}^{x}\left(x-r_{i}\right) H\left(r_{i}\right)}{\sum_{r_{i}=0}^{x} x H\left(r_{i}\right)}
$$

The gray value threshold can be determined by using the relationship curve of the gray value and $\phi(x)$. The critical gray value $c$ corresponds to the abrupt change in gray value. The relationship curve of the gray value and $\phi(x)$ decreased with the increase in the gray value. When the gray value exceeded the value of $c$, the curve increased further and the coal material became visible. Based on the gray level, the CT images can be classified into two categories, namely, one with pores and fractures and the other with materials.

As shown in Figure 6, the minimum point of the curve corresponds to the threshold segmentation value [19]. Pore spaces were observed on the critical left side of the gray value. By contrast, critical coal materials were observed on the right side of the gray value. For any CT image, the corresponding curve between gray value $x$ and porosity $\phi(x)$ can be drawn. The essence of the threshold was to determine the minimum value of the function $\phi(x)$.

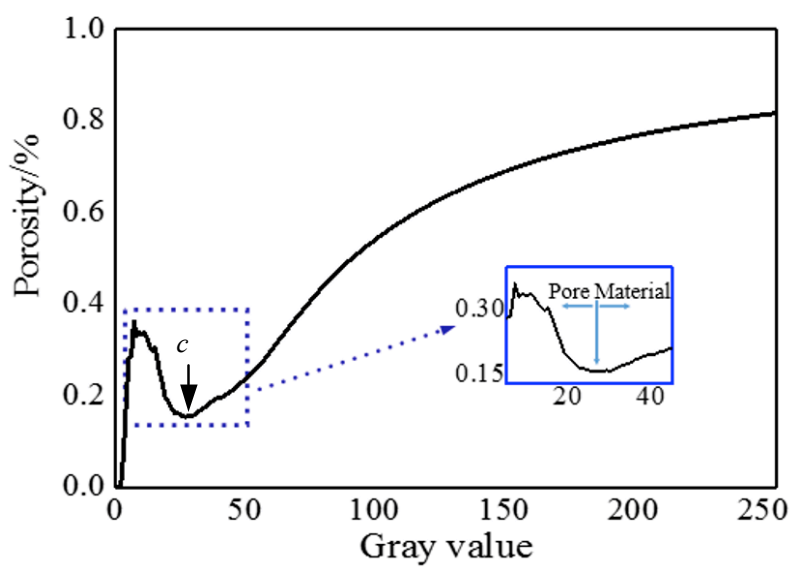

Fig. 6. Relationship curve between image gray value, pore, and material

\section{Result Analysis and Discussion}

\subsection{Digital model for coal microstructure based on CT images}

Based on the aforementioned steps, Shanxi Changzhi anthracite and Anhui Wugou long-flame coal samples in China, which could represent different coal metamorphisms, 
were selected to develop the 3D reconstruction digital model. The coal samples were magnified 100 times. The minimum pore diameter was determined to be over $1.94 \mu \mathrm{m}$. The CT sections were $2,041 \times 2,041$ pixels. The CT sections were cut and $80 \times 80$ pixels CT slices were selected to reflect the coal microstructure and reduce reconstruction calculation difficulty. The size of the 3D model was $80 \times 80 \times 80$ pixels, and the digital model actual size was $0.16 \times 0.16 \times 0.16 \mathrm{~mm}$. Figure 7 shows the 3D digital reconstruction models of Anhui Wugou long-flame coal and Shanxi Changzhi anthracite.

These 3D digital reconstruction models were very small and reached only $0.16 \times 0.16 \times 0.16 \mathrm{~mm}$. These models contained many pores and a large amount of channel information on the "pore throat" scales. When these are combined with CT reconstruction, the following phenomenon can be observed: The bedding structure was evident in raw coal microstructures. Without continuity and anisotropy, coal contains a large number of internal pores. The 3D digital models could reveal the structure of coal, which cannot be reflected by $2 \mathrm{D}$ image information. This method of determining the coal pore structure is more vivid and concrete than that by using SEM.

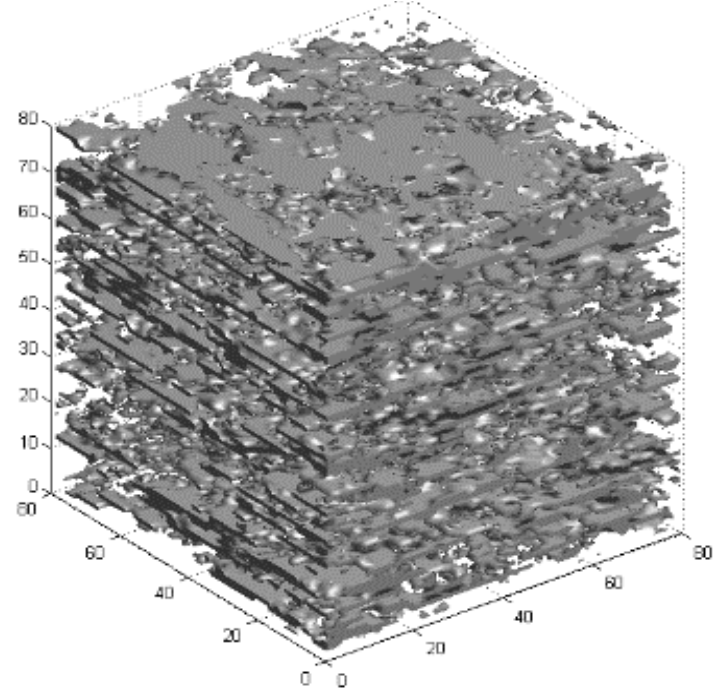

(a)

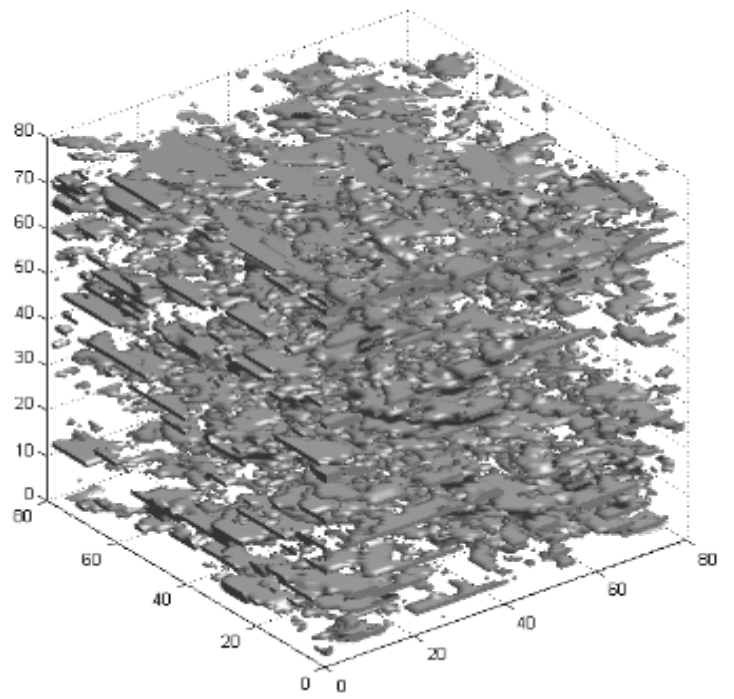

(b)

Fig. 7. Coal microstructure real digital models. (a) Shanxi Changzhi anthracite, (b) Anhui Wugou long-flame coal

\subsection{Porosity measurement of coal digital model and error comparison}

Based on the number of pixels, the $3 \mathrm{D}$ reconstruction model could be considered as a matrix set of pixels [20, 21]. The study used statistical software to analyze the obtained data flow. Then, the porosity of the reconstructed digital models was calculated using Formula (9) [22-24].

$$
\phi=\frac{V_{E}}{V_{T}}=\frac{s^{2} a \sum_{r_{i}=r_{\min }}^{r_{\max }}\left(r_{\max }-r_{i}\right) H\left(r_{i}\right)}{s^{2} a \sum_{r_{1}=r_{\min }}^{r_{\max }}\left(r_{\max }-r_{\min }\right) H\left(r_{i}\right)}
$$

Table 1. DTM threshold segmentation results and porosity of 3D reconstruction models

\begin{tabular}{|c|c|c|c|c|c|c|c|}
\hline \multirow[t]{2}{*}{ Coal } & \multirow{2}{*}{$\begin{array}{l}\text { Statistical } \\
\text { region }\end{array}$} & $\begin{array}{c}\text { DTM } \\
\text { method }\end{array}$ & $\begin{array}{c}\text { 3D } \\
\text { reconstruction }\end{array}$ & \multirow[t]{2}{*}{ Coal } & \multirow{2}{*}{$\begin{array}{l}\text { Statistical } \\
\text { region }\end{array}$} & $\begin{array}{c}\text { DTM } \\
\text { method }\end{array}$ & $\begin{array}{c}\mathrm{3D} \\
\text { reconstruction }\end{array}$ \\
\hline & & Threshold & Porosity (\%) & & & Threshold & Porosity (\%) \\
\hline \multirow{3}{*}{$\begin{array}{c}\text { Shanxi } \\
\text { Changzhi } \\
\text { anthracite } \\
\text { coal }\end{array}$} & $\begin{array}{c}\text { A region } \\
80 \times 80 \times 80 \\
\text { pixels }\end{array}$ & $\begin{array}{l}12 \\
21 \\
30 \\
\end{array}$ & $\begin{array}{l}12.14 \\
14.08 \\
13.21 \\
\end{array}$ & \multirow{3}{*}{$\begin{array}{l}\text { Anhui } \\
\text { Wugou } \\
\text { long- } \\
\text { flame } \\
\text { coal }\end{array}$} & $\begin{array}{l}\text { A region } \\
80 \times 80 \times 80 \\
\text { pixels }\end{array}$ & $\begin{array}{l}17 \\
23 \\
47 \\
\end{array}$ & $\begin{array}{l}17.89 \\
16.34 \\
17.21 \\
\end{array}$ \\
\hline & $\begin{array}{c}\text { B region } \\
80 \times 80 \times 80 \\
\text { pixels }\end{array}$ & $\begin{array}{l}12 \\
19 \\
30\end{array}$ & $\begin{array}{l}12.17 \\
11.69 \\
14.46\end{array}$ & & $\begin{array}{l}\text { B region } \\
80 \times 80 \times 80 \\
\text { pixels }\end{array}$ & $\begin{array}{l}36 \\
28 \\
31\end{array}$ & $\begin{array}{l}16.83 \\
14.71 \\
15.12\end{array}$ \\
\hline & $\begin{array}{c}\text { C region } \\
80 \times 80 \times 80 \\
\text { pixels }\end{array}$ & $\begin{array}{l}32 \\
25 \\
51\end{array}$ & $\begin{array}{l}13.21 \\
13.59 \\
12.83\end{array}$ & & $\begin{array}{l}\text { C region } \\
80 \times 80 \times 80 \\
\text { pixels }\end{array}$ & $\begin{array}{l}36 \\
22 \\
41\end{array}$ & $\begin{array}{l}18.81 \\
16.52 \\
17.13\end{array}$ \\
\hline
\end{tabular}
such, the reconstruction model contained only two gray values, namely, 0 and 1 , Thus, porosity can be calculated as follows:
To characterize objectively the validity of the established model, a pressured-mercury experiment was conducted after the CT scanning. The data were then averaged. In view of an 
isolated phenomenon, Sections A, B, and C in Fig. 4 were selected for the $3 \mathrm{D}$ reconstruction. The porosity of the reconstruction model was also calculated. Table 1 presents the porosities of the models.

As shown in Table 1, the average porosity of Shanxi Changzhi anthracite was $13.04 \%$, and the average porosity of Anhui Wugou long-flame coal porosity was $16.72 \%$. The coal core structure determined using the mercury intrusion method showed that the porosity of Shanxi Changzhi anthracite was $13.37 \%$, and that the porosity of Anhui Wugou long-flame coal was $16.92 \%$. The error between the mercury intrusion method and the digital model of 3D CT reconstruction was $2.4 \%$ for Shanxi Changzhi anthracite and $1.2 \%$ for Anhui Wugou long-flame coal, which showed that the reconstructed model could vividly characterize the micropore structure of coal. The maximum porosity errors of these two types of coal samples were $12.5 \%$ and $13.1 \%$ (as shown in Tab. 1). The effective porosity of the digital model was less than that of the mercury intrusion method, which may be due to the high pressure in the method. The high pressure in the mercury intrusion method could increase the pore volume of coal, and then further increase the coal porosity.

The reconstructed digital model can be gradually optimized to produce a smooth surface, thereby suggesting that 3D CT data could be converted into a CAD-readable file. Current mainstream simulation software, such as Ansys, COMSOL, and Abaqus, can read NURBS-based CAD surface data digital models as well as attain the numerical simulation of gas flow at the microstructure level. Fabrication of these reconstructed models is possible using advances in $3 \mathrm{D}$ printing and other additive manufacturing techniques, thereby radically improving our understanding of the coal microstructure.

\subsection{Limitation of the model}

As per the hypothesis, the coal digital models were established based on CT 2D images; such a process require continuous and non-invasive acquisition of all images. However, this condition is impossible for the coal pillar making process, which is under different geological conditions, especially the small size coal pillar. Furthermore, following the need to simulate when reconstructing the digital model of coal, the existence of closed pores (e.g., dead holes) is ignored, and the pores of coal are regarded as mutual.

\section{Conclusions}

In order to predict the coal body microstructure, the $3 \mathrm{D}$ digital models based on CT images and reconstruction method were respectively used. In the present paper, the problem of coal microstructure digital models based on CT images was reconstructed, and the gray level threshold segmentation method was developed. The porosity of coal digital model was investigated as well as the error between digital model and the experimental results. This paper provides an attempt to characterize quantitatively and visually the pores in coal. The following are the main conclusions.

1) A $3 \mathrm{D}$ coal microstructure reconstruction method was developed based on CT scan images. Among the methodical approach steps, DTM threshold segmentation is an effective technique to obtain binary images. In conformity with the experiment the proposed reconstructed digital model can show the 3D details of coal pore and visually characterize the microstructures as well as show the spatial distribution of the permeability of coal.

2) Using the characteristics of the image itself, the CT image can be divided into two parts, namely, the pore and the framework. DTM threshold segmentation can mitigate the influence of human subjectivity on threshold selection.

3) Results showed that the $3 \mathrm{D}$ reconstruction model produced using CT images can indicate pore spatial distribution in the coal seam and is more effective than the traditional experimental methods. By comparing the porosity obtained by traditional experimental method and reconstruction, we determined that the errors were less than $5 \%$, with a high recognition rate. This result shows that the digital reconstruction models can effectively characterize the coal microstructure.

4) Based on CT reconstruction and reverse engineering technology, the 3D CT data of coal can be transformed into real CAD models, and imported into finite element software for numerical simulation. Due to the irregularity of morphology of pore spaces, the models must be smoothed.

This study can meet the demands for coal pore miscrostructure in the coal mining industry with sucessful application to examples of different degrees of coal. However, the method is limited by special conditions, such as pore connectivity and CT image resolution. Further studies are required to solve the prediction model in special conditions.

\section{Acknowledgements}

This work was supported by the Scientific Research Foundation of State Key Laboratory of Coal Mine Disaster Dynamics and Control (Chongqing University) (2011DA105287-FW201411), National Natural Science Foundation of China (51304128, 51304237), the Program for the Outstanding Young Scientists of Shandong University of Science and Technology (Project No. 2015JQJH105), and the Taishan Scholar Talent Team Support Plan for Advantaged \& Unique Discipline Areas.

\section{References}

1. Li H. Y., Ogawa Y., Shimada, S., "Mechanism of methane flow through sheared coals and its role on methane recovery", Fuel, 82(10), 2003, pp. 1271-1279.

2. Cheng W. M., Zhang. X. Q., ZHANG R., "Experimental study on coal pore characteristic based on cryogenic liquid nitrogen method", Applied Mechanics and Materials, 341-342, 2013, pp. 345-350.

3. Yang B. H., Wu A. X., Wang C. L., "Three-dimensional simulation of pore scale fluid flow in granular ore media with realistic geometry", Transactions of Nonferrous Metals Society of China, 22(12), 2012, pp. 3081-3086
4. Degruyter W, Burgisser A., Bachmann O., "Synchrotron X-ray microtomography and lattice Boltzmann simulations of gas flow through volcanic pumices", Geosphere, 6(5), 2010, pp. 470-481.

5. Golab A., Ward C. R., Permana A., "High-resolution threedimensional imaging of coal using microfocus X-ray computed tomography, with special reference to modes of mineral occurrence". International Journal of Coal Geology, 113, 2013, pp. 97-108.

6. Kawakata H., Cho A., Kiyama T., "Three-dimensional observations of faulting process in westerly granite under uniaxial and triaxial conditions by x-ray CT scan", Tectonophysics, 313(3), 1999, pp. 293305 . 
Wang Gang, Zhang Xiaoqiang, Yang Xinxiang, Sun Lulu and Qu Hongyuan/

Journal of Engineering Science and Technology Review 9 (4) (2016) 177 - 184

7. Vogel H. J., Roth K., "A new approach for determining effective soil hydraulic functions”, European Journal of Soil Science, 49(4), 1998, pp. 547-556.

8. Yang G. S, Xie D. Y., Zhang C. Q., "The quantitative analysis of distribution regulation of CT values of rock damage", Chinese Journal of Rock Mechanics and Engineering, 17(3), 1998, pp. 279-285.

9. Ge X. R, Ren J. X., Pu Y. B., "Rock meso-damage propagation law of CT real-time testing", Science in China (Series E: Technological Sciences), 44(3), 2001, pp. 328-336.

10. Peng R. D., Yang Y. C., Ju Y., "Computation of fractal dimension of rock pores based on gray CT images", Chinese Science Bulletin, 56(31), 2011, pp. 3346-3357.

11. Gong W. L., Li C., "Multi-scale and anisotropic characterization of coal structure based on sem image analysis", Chinese Journal of Rock Mechanics and Engineering, 29(Supp. 1), 2010, pp. 2681-2689.

12. Simons D., Kachelrieß M., Schlemmer H. P, "Recent developments of dual-energy CT in oncology", European Radiology, 24(4), 2014, pp. 930-939.

13. Mahoney S. A., Rufford T E, Rudolph V, "Creation of microchannels in Bowen Basin coals using UV laser and reactive ion etching”. International Journal of Coal Geology, 144-145, 2015, pp. 4857.

14. Wang Y., Li X., Que J. M., "A porosity calculation method based on CT images and its application", Journal of Hydraulic Engineering, 46(3), 2015, pp. 357-365.

15. Tian L., Cao Y. X, Chai X. Z, "Best practices for the determination of low-pressure/permeability coalbed methane reservoirs, Yuwu Coal Mine, Luan mining area, China", Fuel, 160, 2015, pp. 100-107.
16. Wildenschild D., Sheppard A. P., "X-ray imaging and analysis techniques for quantifying pore-scale structure and processes in subsurface porous medium systems", Advances in Water Resources, 51, 2013, pp. 217-246.

17. Karthik K. B., Suresh V. G, Jayathi Y. M., "3D reconstruction and design of porous media from thin sections", International Journal of Heat and Mass Transfer, 73, 2014, pp. 250-264.

18. Wang G., Yang X. X., Zhang X. Q., "Numerical simulation on nondarcy seepage of CBM by means of 3D reconstruction based on computed tomography", Journal of China Coal Society, 41(4), 2016, pp. 931-940.

19. Sheng J. C., Ye M. H., Zhou Z. R., "Reconstruction of 3D digital core and porosity analysis of pore network model", Water Resources and Power, 30(10), 2012, pp. 65-68.

20. Aditya B., Debabrata D. G., Sushanta K. M., "Computation of streaming potential in porous media: Modified permeability tensor", Journal of Computational Physics, 300, 2015, pp. 53-69.

21. Taud H., Martinez-Angeles T. R., Parrot J. F., "Porosity estimation method by X-ray computed tomography", Journal of Petroleum Science and Engineering, 47(3-4), 2005, pp. 209-217.

22. Lamei M., Mirghasemi A. A., "A discrete element model for simulating saturated granular soil”, Particuology, 9(6), 2011, pp. 650658.

23. Naudé G., Hoffman J., Theron S. J., "The use of X-ray computed tomography in the characterisation of coal and associated char reductants", Minerals Engineering, 52, 2013, pp. 143-154.

24. Montemagno, C. D., Pyrak-Nolte, L. J., "Fracture network versus single fractures: Measurement of fracture geometry with X-ray tomography", Physics and Chemistry of the Earth (Part A: Solid Earth and Geodesy), 24(7), 1999, pp. 575-579. 